\title{
Vacancies for JRF/SRF/RA (as per DST, Govt. of India norms)
}

\author{
The National Academy of Sciences, India, 5, Lajpat Rai Road, Allahabad-211002, India, \\ Website: www.nasi.org.in, www.nasi.nic.in, Phone: 91-532-2640244
}

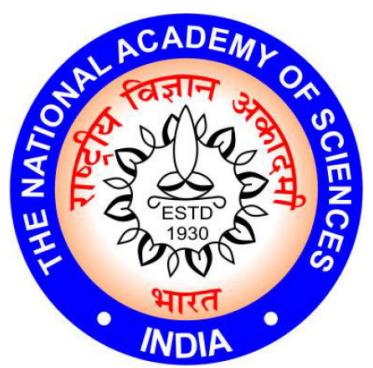

Vacancies for JRF/SRF/RA (as per DST, Govt. of India norms) - The positions are purely temporary.

Applications are invited from the young scientists/researchers to work for the conservation of the river Ganges, as Ganga-Researcher(s). The applicants should have qualification(s) necessary for applying for the position of JRF/ SRF/RA, as per DST, Govt. of India norms. ${ }^{1}$

Last date of receiving the application along with a brief resume (including the date of birth, necessary qualification(s), scientific contributions, research proposal details and contact no, email) is Sept, 30 2015. After scrutiny the shortlisted candidates will be called for the interview to be held shortly in the office of the Academy at Allahabad.

\section{Terms and conditions for the position(s) of NASI-Ganga Research Scholar}

1. The applicant must send a proposal (2 pages only) for the research work to be undertaken, if appointed.

2. If appointed a. The Scholar will initially be appointed for two years.

b. The total emolument to be paid directly to the scholar will be as per his/her position to be decided by the selection committee with the approval of the NASI-Council; he/she may be appointed as JRF/SRF/RA, as per DST, Govt. of India norms.

c. The scholar will work in his/her own institution from where he/she would be nominated for the scholarship.

d. A quarterly report will be required to be submitted by the scholar to the General Secretary, NASI, on the work done by him/her during the period under report.

e. From time to time, as per functional requirement of the Academy the Scholar may be required to be present in the Academy; and render his/her services.

f. A contingent grant of Rs. 50,000/- per annum will also be provided to the scholar through his/her Department/Institution, for travel in connection with the research, expenses on modes of communication, chemicals, stationary etc.

g. The Scholar will acknowledge the name of the Academy/NASI-Ganga Research Scholarship in his/her all the publications during the tenure of the scholarship.

\footnotetext{
${ }^{1}$ Please see the details for the qualification(s) (OM issued by the DST, New Delhi, Govt. of India, dt. October 21, 2014).
} 